\title{
Reigniting CSCL flash themes
}

\author{
Gerry Stahl • Nancy Law $•$ Friedrich Hesse
}

Published online: 23 October 2013

(C) International Society of the Learning Sciences, Inc. and Springer Science+Business Media New York 2013

This journal promised 6 years ago to publish studies on what it termed "CSCL and its flash themes" (Stahl 2007). Rather than devoting single issues to specific topics of timely prominence, we decided to welcome submissions about selected emerging themes of CSCL research on an on-going basis. Accordingly, we set aflame again in the current issue discussion of the topics of argumentation, scripting, and tabletop interfaces. These three areas of computer support for collaborative learning continue to be active foci of CSCL research. To begin the issue, we spark a new theme with a paper on the use of eye-tracking technology to support and to research collaboration, an approach that has not previously been discussed in this journal but has been gathering attention at the ISLS conferences recently. It is noteworthy that research in these flash themes is still not merely a matter of refining the details of well-established findings, but continues to raise fundamental and controversial theoretical and methodological issues from a CSCL perspective.

In introducing their study of gaze perception among dyads of students, Bertrand Schneider and Roy Pea begin with an extended discussion of joint attention. As they document, joint attention is foundational to collaborative interaction and, indeed, to human sociality. From infancy on, people learn to take advantage of different forms and media of joint attention to make intersubjective sense. Any mode of intentionality (whether individual, group, or collective) involves an orientation to some subject matter; communication accordingly requires a coordinated orientation to a shared object, with the understanding that this orientation is shared and with a shared sense of the object's meaning. For two people to solve a problem together-e.g., in a CSCL setting like answering questions about diagrams - the participants must take (or enact) the problem as the same problem and they must see (and describe) the object as the same object (Stahl 2013, Chapter 8; Zemel and Koschmann 2013). This requirement of successful collaboration is complex, multi-modal, subtle, and learned over a lifetime. It involves discourse, gesture, gaze, cognition, social skills,

G. Stahl $(\bowtie)$

Drexel University, Philadelphia, PA, USA

e-mail: Gerry@ijCSCL.org

N. Law

University of Hong Kong, Hong Kong, People's Republic of China

e-mail: Nancy@ijCSCL.org

F. Hesse

Knowledge Media Research Center (KMRC), Tubingen, Germany

e-mail: Friedrich@ijCSCL.org 
tacit practices, etc. In the experiment reported here, the joint attention is investigated in terms of technological support for coordinating the eye gazes of pairs of students. In the experimental condition, students can see where the eyes of their partners are gazing at a computer screen like their own screen. The knowledge of where their partner is looking can then be used as an information source in addition to their audio connection for discourse. Thereby, the fact that they are staring in a similar direction can be elaborated into a sense that they are making shared meaning concerning the jointly intended object. Data collected on gaze was computed into four different quantifiable measures, which were then correlated - for both the experimental and control conditions - with independent measures designed to operationalize learning gains, joint attention, and quality of collaboration (based on Meier et al. 2007). A small-scale qualitative analysis provides additional insight into the different experiences of the two conditions. This investigation demonstrates how eye-tracking technology can be applied to the long-standing interest within CSCL theory in studying joint attention, common ground, intersubjectivity, shared understanding, co-construction of meaning, group cognition, and joint problem space. However, this requires that objective data on gaze be tied to intersubjective meaning making if gaze is to be used as an indicator of joint attention.

One of the most explored topics in CSCL has been the computer support of argumentation (Andriessen et al. 2003; Asterhan and Schwarz 2010; Falcao and Price 2011; Scheuer et al. 2010; Schwarz et al. 2011). The paper by Esra Alagoz combines this focus with the analysis of learning during videogame playing, another important theme for ijCSCL (Bennerstedt et al. 2012; Silseth 2012). She conducts an ethnographic study of 22 teenage boys who were identified as 'disengaged' at school and school-related work. The investigation concludes that in contrast to their performance in school and contrary to expectations based on earlier publications on argumentation, when the subjects chatted in the fantasy multiuser videogame of World of Warfare $(W o W)$ they "engaged in quality argumentation in $81 \%$ of their argumentative exchanges." Thus, the paper contributes to a line of academic argumentation that says educators should learn from game designers how to motivate students or even that they should incorporate computer games in the classroom to teach cognitive skills like arguing logically. It claims that the quality of the argumentative performance of the students is higher in the "informal" context of WoW because the students have a higher sense of control (e.g., in selecting parameters for their digital avatars). It characterizes the digital context as a less alienating, more authentic setting than school for the students to "establish an emotional attachment to the activity and reflect their personal trajectories." Considering that the WoW scenario is the product of an immense corporate design effort and marketing strategy, is highly formally structured, and is intentionally about as removed from the students' physical lives as possible, this seems to be a curious claim. Furthermore, the reportedly "quality" argumentation is rather different from what the theoreticians of argument cited in the literature review had in mind. They envisioned articulate discourses consisting of multiple propositions tightly linked together. The first counter-argument we are presented with from $W o W$ consists entirely of the grunt: "eh". The difference is that discussions of argumentation referred in the classical discussions (e.g., Toulmin 1958) to the imagined ideal mental chain of propositions of an individual philosopher or scientist. In the data from $W o W$, the arguments extend over the brief chat postings of multiple players, reacting to each other. It is here a transactive, collaborative, or group argument, presented not by an individual thinker but by a sequence of interacting members of a team (guild) planning an action (quest). The quality of the argumentation is an attribute of the group interaction, although the data analysis separates it into categories of isolated utterances and then rates $81 \%$ of them as falling into the quality category. This paper raises some important issues for the flash themes of argumentation and gaming: To what extent is 
the undeniable motivation of games like $W o W$ for teenage boys (perhaps especially for disengaged students) a manufactured and manipulated need? Does it reflect a rejection of their conventional life, rather than a potential training ground for it? Or should we adopt a Vygotskian perspective on learning-to-argue by proposing that one can argue first as part of a virtual group and later internalize the skills for individual scholarly cognition in school?

Scripting has, of course, been a flash theme in CSCL since ijCSCL began publishing, and has remained active in recent years (e.g., Onrubia and Engel 2012; Perez-Sanagustin et al. 2012; Pozzi 2011; Rummel et al. 2012). The study reported here by Hannie Gijers, Armin Weinberger, Alieke Mattia van Dijk, Lars Bollen and Wouter Reinder van Joolingen combines scripting with awareness prompts, another researched CSCL intervention. In particular, it applies these measures in an elementary school setting involving drawing scientific diagrams representing photosynthesis processes. The authors argue that such drawings can be educationally productive but that scripting of collaborative drawing has not been explored extensively in the past. Dyads of students - in a scripted, awareness, or control condition - are asked to construct individual diagrams and then combine them in a shared diagram. Although the drawings are intended to aid student comprehension of photosynthesis by providing an additional medium to reading and discussing for the students to individually and collaboratively construct meaning, the quality of the drawings is operationalized as the quantity of concepts from the science lesson that appear in the drawing. Even using this reified measure, the awareness prompts did not have the expected positive effect on the drawing quality. Interestingly, it did stimulate discourse about more of the concepts, but this did not translate into the anticipated effect on the shared drawings. A qualitative look at the dyadic discourse reveals that "when students combine their individual drawings they often feel the need to provide additional explanations considering the meaning of the represented objects." Methodologically, the conditions of scripting and awareness prompts were kept separate in order to demonstrate that they could each have a positive effect on collaborative discourse and drawing. However, at this point in the research it is important to go beyond the affirmation of the possible positive effect of such mechanisms in order to guide educational designers and teachers in how and when to invoke particular instances of them in concrete situations. It is clear that multiple interventions can interfere with each other or result in over-scripting (Dillenbourg 2002). Students at specific ages, knowledge, aptitudes, and social relations may not be responsive to selected prompts. Experienced teachers know how subtle it is to judge a teachable moment and to respond appropriately to guide individual students or small groups effectively. Perhaps if one now combined the two experimental conditions and tailored the script to the dyad based on the awareness measures of the collaboration process, one could discover an effective synthesis.

A recent flash theme in $i j C S C L$ is the use of tabletop interfaces for collaborative learning (Dillenbourg and Evans 2011; Falcao and Price 2011; Higgins et al. 2011). In their contribution to this issue, Roberto Martinez-Maldonado, Yannis Dimitriadis, Alejandra Martinez-Mones, Judy Kay and Kalina Yacef exploit data from tabletop interactions among triads of students to provide "learning analytics" indicators to guide "classroom orchestration" by teachers. Envisioning future classrooms in which student groups are active at multiple tables, they argue that teachers need real-time feedback about how the different groups are doing. Using the dimensions of measuring collaboration from Meier et al. (2007) to classify the student triads as more collaborative or less collaborative, they compare the use by these triads of verbal and/or physical participation in the assigned concept-mapping task. An important contribution of the paper is how the authors supplement the tabletop equipment with special devices designed to identify the speakers and actors. This is needed in order to determine the social network of interaction. The analysis of captured voice and 
object-manipulation actions on the tabletop involved detailed classifications, conducted automatically by the assembled technology. Although the correlations are not statistically significant, they suggest that refined versions of this approach could be useful in identifying, at least post hoc, teams that are behaving less collaboratively than desired. Thus, the authors have succeeded in capturing and automatically analyzing dimensions of interaction around the tabletop, which could in theory prove useful to teachers and even to the students in guiding improved collaboration. While several graphical representations are presented in the paper, the vision of learning analytics providing real-time visualizations of collaborative processes to the participants to guide their interaction remains a distant goal, without having addressed major issues, such as intrusive intervention in the interaction, interpretation of the information by the participants, or strategies for them to repair problems. How are teachers and especially students to make sense of such abstract representations of interaction characteristics in a way that is likely to improve their situated collaborative learning?

Flash themes may flare up or die down over time, but it seems-based on a critical reading of these articles - that the task of CSCL remains unwavering. It must be "centrally concerned with meaning and the practices of meaning making in the context of joint activity, and the ways in which these practices are mediated through designed artifacts" (Koschmann 2002, p. 18). No matter how technological the theme and no matter how objective the methodology, issues of human group meaning making must still be centrally addressed.

\section{Reviewers}

The quality and relevance of papers published in $i j C S C L$ is primarily due to the peer-review process that filters out inappropriate or premature submissions and guides the authors of promising submissions to make the revisions necessary for publication. During the 8 years of $i j C S C L$ publication, the following CSCL researchers conducted 1,537 reviews:

Shaaron Ainsworth, Rick Alterman, Lisbeth Amhag, Jerry Andriessen, Nancy Ares, Baharuddin Aris, Hans Christian Arnseth, Maarit Arvaja, Christa Asterhan, Maria Avgerinou, Gerardo Ayala, Michael Baker, Maria Bannert, Liam Bannon, Ulrika Bennerstedt, Marina Bers, Johanna Bluemink, Daniel Bodemer, Jacqueline Bourdeau, Paul Brna, Bertram Bruce, Amy Bruckman, Juergen Buder, Murat Cakir, Angela Carell, John Carroll, Carol Chan, Rosanna Chan, Tak-Wai Chan, Elizabeth Charles, Clement Chau, Fei-Ching Chen, Gaowei Chen, Britte Cheng, Ming Ming Chiu, Samuel K.W. Chu, Cesar Collazos, Ulrike Cress, Charles Crook, Lucilla Crosta, Ton de Jong, Bram De Wever, Anne Deiglmayr, Muhammet Demirbilek, Sharon Derry, Pierre Dillenbourg, Angelique Dimitrakopoulou, Lone Dirckinck-Holmfeld, Nina Dohn, Gilles Doiron, Paul Dourish, Nathan Dwyer, Anna Engel, Tanja Engelmann, Noel Enyedy, Gijsbert Erkens, Michael A Evans, Deller Ferreira, Frank Fischer, Brian Foley, Andrea Forte, Norm Friesen, Hugo Fuks, Andreas Gegenfurtner, Anne Gerdes, Sean Goggins, Ricki Goldman, Luisa Aleyda Gonzalez, Christian Greiffenhagen, Begona Gros, Jonathan Grudin, Frode Guribye, Joerg Haake, Kai Hakkarainen, Paivi Hakkinen, Raija Hamalainen, Andreas Harrer, Wu He, Libby Hemphill, Thomas Herrmann, Friedrich Hesse, Steven Higgins, Cindy Hmelo-Silver, Christopher Hoadley, Ulrich Hoppe, Christine Howe, Tien-Chu Huang, James Hudson, Diane Hui, Chris Hundhausen, Liisa Ilomaki, Shahrinaz Ismail, Seiji Isotani, Michael Jacobson, Isa Jahnke, Manoj Jain, Sanna Jarvela, Anne Jelfs, Patrick Jermann, Richard Joiner, Christopher Jones, Robert Jorczak, Regina Jucks, Yael Kali, Victor Kaptelinin, Manu Kapur, Anastasios Karakostas, Fengfeng Ke, Liesbeth Kester, Diane Jass Ketelhut, Andrea Kienle, Joachim Kimmerle, Paul Kirschner, Lars Kobbe, Matthew Koehler, Bas Kolloffel, Timothy Koschmann, Ingeborg Krange, Eleni Kyza, Therese Laferriere, Minna Lakkala, Victor 
Lally, Niki Lambropoulos, Mary Lamon, Yu-Ju Lan, Annika Lantz-Andersson, Johann Larusson, Nancy Law, Mark Lee, Erno Lehtinen, Maria Ligorio, Kenneth Lim, Robb Lindgren, Oskar Lindwall, Lasse Lipponen, Eva Lira, Geoffrey Liu, Han-Chin Liu, Jia-Jiunn Lo, Jacques Lonchamp, Chee-Kit Looi, Jingyan Lu, Rose Luckin, Sten R. Ludvigsen, Andreas Lund, Kristine Lund, Johan Lundin, Kim MacKinnon, Alejandra Martinez, Camillia Matuk, Richard Medina, Monika Mital, Naomi Miyake, Anders Morch, Johannes Moskaliuk, Daisy Mwanza-Simwami, Bonnie Nardi, Brian Nelson, Bernhard Nett, Matthias Nackles, E. Michael Nussbaum, Miguel Nussbaum, Angela O'Donnell, Hiroaki Ogata, Claire O'Malley, Javier Onrubia, Jun Oshima, Khaziyati Osman, Roy Pea, Eduardo Penalosa, Mar Parez-Sanagustan, Ruediger Pfister, Manoli Pifarre, Wojciech Podraza, Sara Price, Mingzhu Qiu, Subba Rao, Ingvill Rasmussen, Janet Read, Peter Reimann, Ann Renninger, Jochen Rick, Alan Roberts, Tim Roberts, Jennifer Rode, Markus Rohde, Jeremy Roschelle, Carolyn Rose, Liam Rourke, Nikol Rummel, Nadira Saab, Roger Saljo, Johann Sarmiento-Klapper, Claudia Sassenrath, Marlene Scardamalia, Tammy Schellens, Oliver Scheuer, Bertrand Schneider, Gregg Schraw, Baruch Schwarz, Beat Schwendimann, Anna Sfard, David Shaffer, Wesley Shumar, Amy Soller, Nancy Songer, Hans Spada, Marc Stadtler, Gerry Stahl, Karsten Stegmann, Constance Steinkuehler, Alan Stevenson, Jan-Willem Strijbos, Masanori Sugimoto, Daniel Suthers, Berthel Sutter, Seng-Chee Tan, Steven Tanimoto, Gustav Taxan, Pierre Tchounikine, Meng Yew Tee, Chris Teplovs, Sacip Toker, Ramon Prudencio Toledo, Stefan Trausan-Matu, Michael Tscholl, Nan Uhlik, Jan van Aalst, Marije van Amelsvoort, Ravi Vatrapu, Marjaana Veermans, Patricia Verdines, Chieu Vu Minh, Erin Walker, Sarah Walter, Feihong Wang, Barbara Wasson, Jim Waters, Christof Wecker, Rupert Wegerif, Armin Weinberger, Gordon Wells, Patrick Wessa, Martin Wessner, Tobin White, Alyssa Wise, Donghee Wohn, Volker Wulf, Fatos Xhafa, Kui Xie, Ling Ling Yen, Jennifer Yeo, Fu-Yun Yu, Nicola Yuill, Joyce Yukawa, Jianwei Zhang, Coco Zhao, Joerg Zumbach,

\section{References}

Andriessen, J., Baker, M., \& Suthers, D. (Eds.). (2003). Arguing to learn: Confronting cognitions in computer-supported collaborative learning environments. Dordrecht: Kluwer Academic Publishers. Computer-supported collaborative learning book series, vol 1.

Asterhan, C., \& Schwarz, B. (2010). Online moderation of synchronous e-argumentation. International Journal of Computer-Supported Collaborative Learning, 5(3), 259-282.

Bennerstedt, U., Ivarsson, J., \& Linderoth, J. (2012). How gamers manage aggression: Situating skills in collaborative computer games. International Journal of Computer-Supported Collaborative Learning, $7(1), 43-61$.

Dillenbourg, P. (2002). Over-scripting CSCL: The risks of blending collaborative learning with instructional design. In P. Kirschner (Ed.), Three worlds of CSCL: Can we support CSCL? (pp. 61-91). Heerlen: Open University of the Netherlands.

Dillenbourg, P., \& Evans, M. (2011). Interactive tabletops in education. International Journal of ComputerSupported Collaborative Learning, 6(4), 491-514.

Falcao, T. P., \& Price, S. (2011). Interfering and resolving: How tabletop interaction facilitates co-construction of argumentative knowledge. International Journal of Computer-Supported Collaborative Learning, 6(4), 539-559.

Higgins, S. E., Mercier, E., Burd, E., \& Hatch, A. (2011). Multi-touch tables and the relationship with collaborative classroom pedagogies: A synthetic review. International Journal of Computer-Supported Collaborative Learning, 6(4), 515-538.

Koschmann, T. (2002). Dewey's contribution to the foundations of CSCL research. In G. Stahl (Ed.), Computer support for collaborative learning: Foundations for a CSCL community: Proceedings of CSCL 2002 (pp. 17-22). Boulder: Lawrence Erlbaum Associates. 
Meier, A., Spada, H., \& Rummel, N. (2007). A rating scheme for assessing the quality of computer-supported collaboration processes. International Journal of Computer-Supported Collaborative Learning, 2(1), 63-86.

Onrubia, J., \& Engel, A. (2012). The role of teacher assistance on the effects of a macro-script in collaborative writing tasks. International Journal of Computer-Supported Collaborative Learning, 7(1), 161-186.

Perez-Sanagustin, M., Santos, P., Hernandez-Leo, D., \& Blat, J. (2012). 4sppices: A case study of factors in a scripted collaborative-learning blended course across spatial locations. International Journal of ComputerSupported Collaborative Learning, 7(3), 443-465.

Pozzi, F. (2011). The impact of scripted roles on online collaborative learning processes. International Journal of Computer-Supported Collaborative Learning, 6(3), 471-484.

Rummel, N., Mullins, D., \& Spada, H. (2012). Scripted collaborative learning with the cognitive tutor algebra. International Journal of Computer-Supported Collaborative Learning, 7(2), 307-339.

Scheuer, O., Loll, F., Pinkwart, N., \& McLaren, B. (2010). Computer-supported argumentation: A review of the state of the art. International Journal of Computer-Supported Collaborative Learning, 5(1), 43-102.

Schwarz, B. B., Schur, Y., Pensso, H., \& Tayer, N. (2011). Perspective taking and synchronous argumentation for learning the day/night cycle. International Journal of Computer-Supported Collaborative Learning, 6(1), 113-138.

Silseth, K. (2012). The multivoicedness of game play: Exploring the unfolding of a student's learning trajectory in a gaming context at school. International Journal of Computer-Supported Collaborative Learning, 7(1), 63-84.

Stahl, G. (2007). CSCL and its flash themes. International Journal of Computer-Supported Collaborative Learning, 2(4), 359-362.

Stahl, G. (2013). Translating Euclid: Creating a human-centered mathematics (e-book ed.). Morgan \& Claypool Publishers.

Toulmin, S. (1958). The uses of argument. Cambridge: Cambridge University Press.

Zemel, A., \& Koschmann, T. (2013). Online math problem solving as a process of discovery in CSCL. International Journal of Computer-Supported Collaborative Learning, 8(1). 